\title{
Violence permeating daily life: a qualitative study investigating perspectives on violence among women in Karachi, Pakistan
}

This article was published in the following Dove Press journal:

International Journal of Women's Health

I November 2012

Number of times this article has been viewed

\section{Tazeen S Ali ${ }^{1,2, *}$ \\ Gunilla Krantz ${ }^{3}$ \\ Ingrid Mogren ${ }^{4, *}$}

'School of Nursing, Aga Khan University, Karachi, Pakistan;

${ }^{2}$ Department of Public Health Sciences, Division of Global Health, Karolinska Institute, Stockholm, ${ }^{3}$ Department of Public Health and Community Medicine/Social Medicine, The Sahlgrenska Academy at University of Gothenburg, Gothenburg, ${ }^{4}$ Department of Clinical Sciences, Obstetrics and Gynecology, Umeå University, Umeå, Sweden

*These authors contributed equally to this work
Correspondence: Tazeen Saeed Ali School of Nursing and Department of Community Health Sciences, Aga Khan University, Karachi, Pakistan

Tel +92 2l 3493005 I

Fax +92 21 4934294

Email tazeen.ali@aku.edu
Background: This study explored how married women perceive situations which create family conflicts and lead to different forms of violence in urban Pakistan. In addition, it examines perceptions of consequences of violence, their adverse health effects, and how women resist violence within marital life.

Methods: Five focus group discussions were conducted with 28 women in Karachi. Purposive sampling, aiming for variety in age, employment status, education, and socioeconomic status, was employed. The focus group discussions were conducted in Urdu and translated into English. Manifest and latent content analysis were applied.

Results: One major theme emerged during the analysis, ie, family violence through the eyes of females. This theme was subdivided into three main categories. The first category, ie, situations provoking violence and their manifestations, elaborates on circumstances that provoke violence and situations that sustain violence. The second category, ie, actions and reactions to exposure to violence, describes consequences of ongoing violence within the family, including those that result in suicidal thoughts and actions. The final category, ie, resisting violence, describes how violence is avoided through women's awareness and actions.

Conclusion: The current study highlights how female victims of abuse are trapped in a society where violence from a partner and family members is viewed as acceptable, where divorce is unavailable to the majority, and where societal support of women is limited. There is an urgent need to raise the subject of violence against women and tackle this human rights problem at all levels of society by targeting the individual, family, community, and societal levels concurrently.

Keywords: violence against women, domestic violence, women's perceptions, gender inequality, empowerment, qualitative study, Pakistan

\section{Introduction}

Violence against women is a major public health issue throughout the world. ${ }^{1-3}$ Violence against women in the form of physical, sexual, or psychological violence and abuse is more commonly seen in countries where the level of gender equality is comparatively low, traditional gender roles are practiced, and communities have high unemployment rates and low social cohesion. ${ }^{4,5}$ In some countries, interventions have been implemented to control violence, for example, by creating awareness among community organizations for violence against women and human rights. ${ }^{6-10}$ Measures need to be taken to address social norms and behaviors among men who practice violence against their female partners; however, few studies report on such interventions. ${ }^{11}$ Furthermore, there is a lack of available legal frameworks to protect women from such violations. ${ }^{4}$ 
Qualitative studies globally present an indepth understanding of marital violence towards women, and its negative health consequences. ${ }^{12,13}$ The consequences vary depending on the level of gender equality, masculinity norms, and other cultural norms, as well as socioeconomic development. ${ }^{13}$ Violence against women may stay unacknowledged because women either interpret the violence inflicted on them as a part of normal daily life or they do not know where to seek help. Women may also hide exposure to violence due to social stigma. ${ }^{14}$ Globally, violence against women also prevents women from taking equal part in economic and social life, and as a consequence, comparatively few women hold decision-making positions in society. ${ }^{4}$

Pakistani women are expected to rear children, perform domestic work, be submissive, and obey the husband and his family, and it is common for husbands and in-laws in Pakistan to restrict women's reproductive autonomy and limit their rights and decision-making power. ${ }^{15}$ Better educated women are in a better position, given that it is more likely that they have a professional career, but such privileged women form a small minority of all women living in Pakistan. ${ }^{16}$

We have previously demonstrated a very high prevalence of physical, sexual, and psychological violence, and its associated adverse health effects in Pakistan. ${ }^{17}$ Other studies also report on serious health consequences, such as anxiety, depression, adverse physical and sexual outcomes, and death. ${ }^{18,19}$ Studies are also available on violence during and after pregnancy. These report a high prevalence of physical, sexual, and psychological violence, not only from the partner but also from in-laws. The risk factors identified include the level of the woman's education, consanguinity, and duration of marriage. ${ }^{6,20-23}$ Most studies on violence against women in Pakistan have applied a quantitative study design; however, few studies have qualitatively explored women's perceptions and ways in which they resist violence.

This study explored how married women perceive situations that create family conflicts from which follow different forms of violence. We further explored women's perceptions of the consequences of violence, the adverse effects on health, and how women resist violence within marital life in urban Pakistan.

\section{Materials and methods}

This study was carried out in five areas of differing socioeconomic status in urban Karachi, Pakistan. Five focus group discussions with married women were conducted using a qualitative study design. After approval by the institutional ethical review committee of the Aga Khan University in
Karachi, the study used purposive sampling with the following criteria: age 20-60 years; employed or unemployed; and residence in different socioeconomic areas (upper, middle, and lower socioeconomic areas). The informants were invited by community health workers or teachers, who were acting as community facilitators, to participate in the study without inquiring if they had any experiences of violence within their marital life. The study per se did not intend to include women who had communicated that they had been exposed to violence, since such a situation could have been hazardous for the safety of the women concerned. During the focus group discussions, no inquiries were made about the participating women concerning their own previous exposure to violence. They were asked to convey their perceptions and experiences of violence in general. Fifty married women were invited and 28 agreed to participate. The reason for refusal was not inquired about. Informants aged 20-40 years were considered "younger" and women aged 41-60 years were considered "older". Background information on the informants is presented in Table 1. The focus group discussions were conducted from June through August 2010. All focus group discussions were conducted in Urdu. To ensure privacy, the focus group discussions were conducted in a home of one of the participating women or at a nongovernmental organization office. Data collection continued until data saturation was reached. Each focus group was homogenous in terms of participant age, socioeconomic status, and employment status. The focus group discussions lasted from 80 to 120 minutes and were led by a moderator (TSA) and a field supervisor who took notes and made observations. All the participants agreed to have their focus group discussions taperecorded. These recordings were transcribed in 7-10 days. The recorded discussions were then compared with the transcripts for verification by the first author (TSA). The documents were thereafter translated into English.

The research team developed a thematic focus group discussion guide that included the following questions (other questions were also asked): "Which situations increase violence against women?", "Which situations in daily life might provoke violence from the husband?", "What kind of violence does a woman have to face?", and "How do women cope with their situation?" Qualitative content analysis was used to interpret the manifest content (what the text says) and the latent content (the interpreted meaning). ${ }^{24}$ Content analysis is a stepwise analytical process. ${ }^{24}$ At the first step, the data were read several times to reach an understanding. Thereafter, the data were divided into meaning units that were condensed and labeled with a code by the first author (TSA). The last author (IM) coded part of the material. 
Table I Characteristics of informants in the focus group discussions

\begin{tabular}{|c|c|c|c|c|c|c|}
\hline FGD & Informants (n) & $\begin{array}{l}\text { Employment } \\
\text { status }\end{array}$ & $\begin{array}{l}\text { Mean age, years } \\
\text { (range) }\end{array}$ & $\begin{array}{l}\text { Mean number } \\
\text { of children (range) }\end{array}$ & $\begin{array}{l}\text { Geographic area } \\
\text { in Karachi and SES }\end{array}$ & $\begin{array}{l}\text { Schooling } \\
\text { in years }\end{array}$ \\
\hline I & 7 & Housewives & $33.7(25-40)$ & $2.0(I-5)$ & Haideri, Aysha, Manzil (middle SES) & 10 to 14 years \\
\hline 2 & 5 & Employed & $45.0(40-60)$ & $2.6(2-3)$ & Defense (upper SES) & 12 to 16 years \\
\hline 3 & 5 & Housewives & $30.2(27-34)$ & $0.6(0-2)$ & Koi Goth (lower and middle SES) & 10 to 16 years \\
\hline 4 & 6 & Employed & $36.2(25-45)$ & $1.7(0-3)$ & $\begin{array}{l}\text { Nazimabad, Karimabad (middle and } \\
\text { upper SES) }\end{array}$ & 12 to 16 years \\
\hline 5 & 5 & $\begin{array}{l}\text { Temporary } \\
\text { work }\end{array}$ & $44.6(38-53)$ & $2.6(0-5)$ & Orangi town (lower SES) & $\begin{array}{l}\text { No formal } \\
\text { schooling }\end{array}$ \\
\hline
\end{tabular}

Abbreviations: FGD, focus group discussions; SES, socioeconomic status.

The coding by the first and last authors was then compared and consensus was reached. Next, the codes were further analyzed and categorized into subcategories by the first and last authors. The refining of subcategories, identification of the three main categories, and development of the theme were done by all authors. All authors read, discussed, and agreed on the final categorization and theme.

One major theme emerged during the analysis, ie, "family violence through the eyes of females". This theme was divided into three main categories, ie, "situations provoking violence and their manifestations", "actions and reactions to violence", and "resisting violence". These main categories were built on the identified subcategories and categories (Table 2).

\section{Situations provoking violence and their manifestations}

This main category describes situations and circumstances provoking violence, sustaining of violence, and the understanding of violence practiced within families.

\section{Arranged marriage and its consequences}

Traditional gender roles were considered a source of conflict for the participants. An arranged marriage (where a life partner is chosen by the family with limited input from the individual) is a common cultural practice in Pakistan. In an arranged marriage, the husband might not accept his wife and as a result pay little attention to her, spending most of his time outside the home.

In arranged marriages, the husband does not spend time with his wife. Such marriage, where a man does not like his wife and has an affair outside, he shows his good mood outside the home, and when he is back at home, where a wife is waiting for him, he neglects her feelings, wishes, and needs (focus group discussion 3 ).

However, it was also reported by middle-class women that today women and men could choose their partner as long as their parents agree with their selection.

\section{Expectations of dowry}

Dowry was considered a strong cultural tradition in Pakistan. According to the participants, dowry helped in assuring respect and was protective against disgrace, shame, taunting, or burning. Girls who lacked a dowry remained unmarried or were forced to marry older men. If a married woman left her husband's home due to conflict or violence, she would relinquish all rights to her dowry.

\section{Husband reserving the right to violate his wife}

Almost all the focus group discussions reported that current gender roles allow a husband to act violently towards his wife. A husband could act violently if his wife did not follow his instructions, did not satisfy him sexually, or gave birth to females. Physical violence was considered common in families of lower socioeconomic status, among ethnic minority groups, and among those who were illiterate.

\section{Financial constraints within the family}

Low and middle socioeconomic participants considered financial constraints to be the most important factor causing violence. To ask for more housekeeping money from a husband who could not afford it could lead to violence against the wife. Women belonging to poor families were unable to seek divorce or separation, because their parents were seldom able to care for their daughter and her children.

We observe that when a month starts, ... then he (the husband) contributes a specified amount to his wife and in this way makes life difficult for her. She has to manage all the daily activities with this small amount. If the wife asks for more money, the husband calls the woman argumentative and at times this results in physical violence (focus group discussion 4).

\section{Misinterpretation of religion}

Misinterpretation of the Muslim religion was considered a cause of violence because some men considered extramarital 
Table 2 Theme, main categories, categories, and subcategories illustrating women's perceptions of situations provoking violence and women's actions after exposure to violence

\begin{tabular}{|c|c|c|c|}
\hline Theme & Main categories & Categories & Subcategories \\
\hline \multirow[t]{7}{*}{$\begin{array}{l}\text { Family violence } \\
\text { through the eyes } \\
\text { of females }\end{array}$} & $\begin{array}{l}\text { Situations provoking violence } \\
\text { and their manifestations }\end{array}$ & $\begin{array}{l}\text { Circumstances provoking } \\
\text { violence }\end{array}$ & $\begin{array}{l}\text { - Arranged marriage and its consequences } \\
\text { - Expectations of dowry } \\
\text { - Husband reserving the right to violate his wife } \\
\text { - Financial constrains within the family } \\
\text { - Misinterpretation of religion } \\
\text { - Self-provoking grounds for violence }\end{array}$ \\
\hline & & Sustaining of violence & $\begin{array}{l}\text { - Obeying the master and tolerating violence } \\
\text { - Hiding violence } \\
\text { - Accepting male aggressive behaviour }\end{array}$ \\
\hline & & $\begin{array}{l}\text { Perpetrators and } \\
\text { understanding of violence }\end{array}$ & $\begin{array}{l}\text { - Violence exerted by close family member } \\
\text { - Women's understanding of violence }\end{array}$ \\
\hline & $\begin{array}{l}\text { Actions and reactions to } \\
\text { violence exposure }\end{array}$ & $\begin{array}{l}\text { Consequences of ongoing } \\
\text { violence }\end{array}$ & $\begin{array}{l}\text { - Exposure to violence negatively affects } \\
\text { women's physical and mental health } \\
\text { - Children experiencing violence in the family } \\
\text { - Situations resulting in divorce }\end{array}$ \\
\hline & & Suicide as the final solution & $\begin{array}{l}\text { - Situations evoking suicidal thoughts } \\
\text { - Suicide when there is no other option left }\end{array}$ \\
\hline & Resisting violence & Women practicing their rights & $\begin{array}{l}\text { - Women taking a stand } \\
\text { - Younger generation's awareness and approach }\end{array}$ \\
\hline & & Capability of women & $\begin{array}{l}\text { - Women managing issues and improving } \\
\text { situations } \\
\text { - Couples understanding }\end{array}$ \\
\hline
\end{tabular}

relationships to be a sin for women but not for men. The participants further stated that there is an incorrect belief among men that Islam allows men to have multiple wives without seeking permission from the existing wife. However, informants were of the opinion that Islam provides rights for women and even proclaims gender equality and respect; however, many men do not accept this interpretation.

\section{Self-provoking grounds for violence}

Being argumentative and wearing inappropriate clothing were ways in which women were thought to create grounds for violence from their husband and from others:

Whenever a wife uses her tongue, then the husband uses his hands. So it's better for a woman to control her tongue (focus group discussion 4).

\section{Sustaining violence}

Informants shared that a woman has to learn to place her husband after God and follow her husband's instructions. Therefore, a woman has to accept her husband's egoistic and superior behavior. If a woman were to share her experiences of violence with her own mother, she would often be told to compromise and tolerate the violence. The informants stated that women are generally taught to believe that men are socialized into becoming short-tempered and violent.
Due to this, it was a woman's responsibility to change her behavior to avoid provoking her husband. It was considered a task for the woman to keep her husband in good spirits and make his life easier.

Women suppressed themselves and avoided sharing their experiences of violence to protect the family honor and their children. A wife was expected to favor her husband always and hide his negative attitude. A woman could also hide her injuries to avoid being blamed or stigmatized:

She tells the doctor that she slipped, being scared that a police case will otherwise be registered. She is afraid of her husband and that he will further beat her. Finally, she will return to his home (focus group discussion 1).

\section{Violence perpetrated by close family members}

A majority of the participants reported that for women living in an extended family it was not uncommon to be disrespected by the mother-in-law or the sisters-in-law. Violence was more often directed at poor women, uneducated women, and women who did not bring a large dowry. If a couple was infertile or had a female child, attitudes towards the woman could become extremely negative. If a woman's husband worked outside the city or country, a brother-in-law or even the father-in-law might demand to have sex with her. 


\section{Women's understanding of violence}

The informants defined violence as physical abuse from a husband towards his wife. Physical violence was defined as a husband hitting his wife with his hands or a stick, kicking his wife, throwing his wife or children on the floor, and beating his pregnant wife. Physical violence was more easily recognized than emotional violence. Emotional violence was described as a husband's use of abusive language, threatening to divorce his wife, or degrading her in front of others. Behaviors such as preventing the wife from entering into paid employment or not allowing her to decide on household matters were also considered types of emotional violence. Sexual violence was defined to occur when a husband forces his wife to have sex against her will, during pregnancy, during the post-partum period, or menstruation, and demanding anal sex. Educated men were perceived to be less likely to perform marital rape.

\section{Actions and reactions to violence}

This main category describes the physical and mental consequences of violence for women and their children, including those that result in suicidal thoughts and actions.

\section{Exposure to violence negatively affects women's physical and mental health}

Informants conveyed that sexual violence often caused physical and psychological pain and sometimes sexually transmitted diseases. Exposure to abusive language concerning the woman herself or her parents and the absence of a person to confide in, could result in frustration, powerlessness, and social isolation. Exposure to violence from a husband might give rise to feelings of hatred towards him and feelings of detachment; however, the wife had to continue their normal family life because no other options were available. In a strained situation, women reported symptoms such as headaches, pain, depression, other mental illness, and ultimately suicide attempts:

There was a statement from my client; she was suffering from sexual violence. She said that (due to sexual violence) 'every night I am dying and every day I feel I am alive again', which means that she was experiencing sexual violence daily at night. These were her feelings and at the end, she went into a depression and then attempted suicide (focus group discussion 4).

\section{Children experiencing violence in the family}

To stay in the home when the mother was repeatedly exposed to violence from the father eventually made the children want to avoid the home; however, this exposed them to other social risks. A daughter who has to witness her father or any other male person use violence towards her mother might perceive that all men use violence. Similarly, a son who is to witness violence against his mother may think that such behaviour is a male norm. Thus, abusive behavior was thought to be passed on to the children.

\section{Situations resulting in divorce}

Informants reported that lack of understanding between partners, illiteracy on behalf of one of the partners, economic limitations, and female infertility often resulted in marital conflict.

If a husband is not strong and can't pay fees for his children and run the house, he will eventually run away from his responsibilities and leave his family alone (focus group discussion 4).

Such conflicts had a potential to create extreme forms of violence and end up with a divorce requested by the husband. Other reasons for divorce included when a wife who gave birth only to daughters or when the wife was unable to satisfy her husband sexually. These reasons for divorce were considered common in all socioeconomic classes. The participants' understanding was that society considers divorce primarily as a male right. However, it was also reported that a woman could ask for a divorce for specific reasons, such as sexual harassment from a father-in-law or a brother-in-law, or if she was a victim of physical violence.

If there is no male child, and another daughter is born, inlaws force the husband to request divorce. Even in maternity homes when a woman still is in the labor room, her husband's family is ready with divorce papers (if a daughter is born) (focus group discussion 4).

\section{Suicide as the final solution}

The informants believed that women exposed to physical violence would develop depression and be at risk of suicidal thoughts. Reasons for such serious symptoms were inability to divorce, financial limitations, or living with an unemployed husband. When a woman exposed to violence tries to discuss her problems with other people, her in-laws consider this as bad behavior. Exposure to violence and lack of people to confide in could also lead to suicidal thoughts. However, having children was protective against suicidal thoughts.

Women exposed to recurrent sexual violence or other forms of violence are likely to become depressed and be at high risk of a suicide attempt. The perceived time between 
exposure of violence and attempted suicide varied greatly. Women from the lower socioeconomic strata were considered to be more prone to commit suicide in relation to women belonging to higher socioeconomic strata. Burning oneself or drinking insecticides were discussed as methods of committing suicide. However, when relatives killed a woman in the family, this was often falsely labeled as suicide.

\section{Resisting violence}

This main category describes how violence is avoided through women's and the younger generation's awareness and actions.

\section{Women taking a stand}

The growing awareness among women about their human rights was discussed. Informants believed that educated women were more likely to stand up for their rights as compared with poorly educated or illiterate women. It was reported that women were able to threaten their husband with divorce, but most husbands wanted to avoid divorce, as it is the custom to pay money to the wife if a divorce is granted. The "modern woman" also tended to share her experiences of exposure to violence with her parents, friends, and occasionally with the mass media to raise support for divorce or separation. Daughters were encouraged to get an education so that future generations could avoid these situations. Illiterate women were considered to need educational awareness sessions to become more aware of their rights.

\section{Awareness in younger generations}

As compared with older women, younger women were considered to be more aware about their rights and therefore less likely to tolerate physical violence from a husband and more likely to demand money from their husband if a divorce was granted. This was considered particularly common among women from educated or wealthier families. Educated young men were considered less concerned about receiving a dowry from their wife and more likely to have been taught by their mothers to respect women in general:

I have seen that now the trend is changing about dowry.

Many educated families will not give or ask for it (focus group discussion 4).

\section{Women managing issues and improving situations}

To resist violent situations, it was considered necessary for a woman to sacrifice her own needs for the sake of her children and in-laws, which would lead to a better life for all of them.
If a sister or brother-in-law needs any help, a woman always tries to help willingly (focus group discussion 3).

Educated women were thought to deal better with their husbands. Community counseling programs were mentioned as being helpful when it came to marital conflicts:

In our community, a program has started in which respected elderly women are available. When a conflict arises in a family such women will listen to both sides. So we feel it is good that the community tries to solve marital issues and those marriages do not end in divorce (focus group discussion 4).

\section{Couples understanding}

Mutual understanding was thought to decrease intimate partner violence. Understanding was more likely to occur when a husband and wife agreed about gender roles, shared similar values, and were close to the same age. Communication skills, premarital counseling, mutual trust and respect, understanding, acceptance, patience, and sincerity were considered important factors. To live in a nuclear family in a loving marriage rather than in an arranged marriage improved the likelihood of mutual understanding.

\section{Discussion}

In this study, the subjects were all familiar with violence against women and its different manifestations. Violence was seen as common in marital life and within the extended family. The marital violence reported in this study may be regarded as a product of asymmetrical power relationships that negatively influence family relations. Women were victims of a number of practices, such as arranged marriages, the extended family system, and the provision of dowry, all of which are serious violations of women's human rights. Informants described adverse health outcomes as well as attempted or completed suicide as results of violence exposure. However, there were also examples of resistance to violence that eventually improved the situation for abused women.

Arranged marriages were acknowledged as being deeply rooted in tradition and culture; however, these arranged marriages were considered to be potential sources of conflict in marital life. Previous studies from similar geographical areas have report conflicting results concerning arranged marriages. ${ }^{25}$ In an Indian study, life satisfaction was reported to be positively related to whether the marriage was by choice, ${ }^{26}$ whereas another study from India reported that women in love-based marriages are more exposed to violence than women in arranged marriages. ${ }^{25}$ 
Previous studies from Pakistan are in support of our findings that infertility, lack of dowry, or not being able to produce a son were factors that often result in violence. ${ }^{15} \mathrm{We}$ also found that some women were exposed to sexual violence perpetrated by their father-in-law or a brother-in-law. To the best of our knowledge, the finding of sexual exploitation within the extended family has not been reported previously in the Pakistani context.

Another finding of this study was that women could tolerate, accept, or hide exposure or effects of violence to protect the family honor. Furthermore, a woman's behavior, ie, passive obedience, has been reported to protect her from verbal threats, physical injuries, and divorce in other studies. ${ }^{15,27}$

In this study, it was generally acknowledged that women exposed to violence could develop physical and mental illness, including suicidal thoughts and suicide attempts. Women, who were stressed continuously due to family conflicts and exposure to violence, including sexual violence, were more prone to develop suicidal thoughts. Women from lower socioeconomic strata who came to a situation of suicidal thoughts were considered to be at higher risk of committing suicide compared with women belonging to higher socioeconomic strata. Women from higher socioeconomic strata were more likely to stand up for themselves and to seek divorce as a way to escape violence. Suicidal inclination among women of lower socioeconomic status may be related to lack of support from the family or society. Suicidal thoughts and attempts may develop when society does not address the root of the problem, leaving vulnerable women exposed to violence. ${ }^{28}$ If steps are not taken, these women may consider suicide as the only available solution to their unbearable situation. However, having children or an unmarried sister was seen as protective against suicide. In addition, violence against women was seen to influence children's behavior in negative ways, and make it more likely that violent behavior is transferred to the next generation. This phenomenon has previously been reported. ${ }^{29}$

Misconceptions related to misinterpretation of the Muslim religion were mentioned as causes of violence. A study from Iraq found that women, due to misinterpretation of religious dogma, do not consider violence against women a crime. ${ }^{31}$ Another study found that women considered men's multiple marriages without the consent of the spouse as a religious misconception. ${ }^{31}$

We found clear indications of a growing awareness of women's rights among females and the younger generation, and of strategies for dealing with violence against women in the family and in society at large. We have previously reported that education holds a central position in this process, ${ }^{32}$ and that the mass media may play an important role in advocating for women's rights. Education has further been identified as one of the most powerful tools for improving quality of life for children. ${ }^{33}$

In summary, our findings point to serious violations of women's human rights, ingrained in general family life and supported by cultural and religious beliefs. To address such violations, a multisector response in terms of policy and action are needed. ${ }^{34}$ Not least is the political will needed to acknowledge this obvious gender inequality situation coupled with a readiness to transform gender norms and to improve the general educational level among girls and boys, and women and men. Primary prevention strategies should be undertaken by the government, which is obligated by international agreements to address violence against women. Such strategies should include protection and justice for victims, raising awareness in communities, expanding access to comprehensive services and other efforts to empower women and also address men. ${ }^{35}$ Initiatives to reduce partner violence further require commitment and vision by the international community, local governments and civil society, and a good example of the latter is the United Nations campaign against violence, ie, "Women Won't Wait", an international coalition of organizations and networks from the global south and north, struggling for women's human rights and health and to end all forms of violence against women. (http://www.womenwontwait.org/). Further, our findings point to a growing awareness and strength particularly among younger women, and such signs of empowerment need support from local organizations, but the health sector also needs to be strengthened and ready to offer professional support to victims.

\section{Strengths and limitations}

To obtain such sensitive data as presented in this study demands thorough planning throughout the research process. The first author was competent in the local language (TSA) and the cultural meaning of the content. Credibility was maintained by selection of setting and informants, and by the development of well structured focus group discussions. Two of the authors (TSA and IM) agreed in the way the codes and subcategories were labeled and categorized, which in the later stages were revised and verified together with the second author (GK). This process secured the confirmability of the study. Transferability was achieved through purposive selection of informants with different background characteristics, such as age, employment status, educational level, and socioeconomic status. The results of this study can probably 
be extended to other people living in similar settings where women are treated in a similar fashion. However, the small sample size may limit its transferability in a broader sense. ${ }^{36}$ Dependability was enhanced by conducting the focus group discussions for two months to ensure that the phenomena under study did not change. ${ }^{24}$ During the analytical process, all the authors discussed thoroughly the structure of subcategories, categories, main categories, and themes, and they all agreed on the final categorization. A limitation of the study is that data were only collected from married women. To reach a multifactorial understanding of the issue of intimate partner violence in Pakistan, the perspectives of both genders are needed. However, the research group included individuals experienced in the scientific method used and the cultural setting, and all authors participated during all stages in the research process.

\section{Conclusion}

The current study describes how women's human rights are violated within marriage and in the extended family, and how the power gradient, with men being considered superior, results in physical, sexual, and emotional violence against women. Female victims of abuse are trapped in a society where violence from a partner or other family members is viewed as acceptable, where divorce is not an option for the majority, and where societal support for women is limited. There is an urgent need to raise the subject of violence between couples and tackle this human rights problem at all levels of societal organization by targeting the individual, family, community, and societal levels simultaneously.

\section{Acknowledgments}

This study was made possible by a grant from the Swedish Foundation for International Cooperation in Research and Higher Education and by support from the Swedish Institute. This study has also been supported by the Department of Public Health Sciences, Division of Global Health, Karolinska Institute, Stockholm, Sweden and the School of Nursing and The Community Health Department at Aga Khan University, Karachi, Pakistan. The Department of Clinical Sciences, Obstetrics and Gynecology, Umeå University, Sweden, gave support during the phase of analysis and manuscript preparation. We want to acknowledge the contributions of Raisa Gul and Nargis Asad, Aga Khan University, Pakistan, and Eva Johansson, Karolinska Institute, Sweden, and Nordic School of Public Health, Gothenburg, Sweden.

\section{Disclosure}

There is no declaration of conflicting interest from any author in this work.

\section{References}

1. Feder G, Griffiths C, MacMillan H. Zero tolerance for domestic violence. Lancet. 2005;365(9454):120.

2. Naeem F, Irfan M, Zaidi QA, Kingdon D, Ayub M. Angry wives, abusive husbands: relationship between domestic violence and psychosocial variables. Womens Health Issues. 2008;18(6):453-462.

3. Krug EG, Mercy JA, Dahlberg LL, Zwi AB. The world report on violence and health. Lancet. 2002;360(9339):1083-1088.

4. Walby S. Gender, globalisation, and democracy. Gend Dev. 2000;8(1): $20-28$.

5. Xu X, Kerley KR, Sirisunyaluck B. Understanding gender and domestic violence from a sample of married women in urban Thailand. J Fam Issues. 2011;32(6):791.

6. Breiding MJ, Ziembroski JS, Black MC. Prevalence of rural intimate partner violence in 16 US states, 2005. J Rural Health. 2009;25(3):240-246.

7. Hamzeh B, Garousi Farshi M, Laflamme L. Opinions about potential causes and triggers of intimate partner violence against women: a population-based study among married men from Kermanshah city, Iran. Int J Inj Contr Saf Promot. 2008;15(4):253-263.

8. Leppakoski T, Astedt-Kurki P, Paavilainen E. Identification of women exposed to acute physical intimate partner violence in an emergency department setting in Finland. Scand J Caring Sci. 2011;24(4): 638-647.

9. Lockart I, Ryder N, McNulty AM. Prevalence and associations of recent physical intimate partner violence among women attending an Australian sexual health clinic. Sex Transm Infect. 2011;87(2):174-176.

10. Gill R, Stewart DE. Relevance of gender-sensitive policies and general health indicators to compare the status of South Asian women's health. Womens Health Issues. 2010;21(1):12-18.

11. García-Moreno C. Dilemmas and opportunities for an appropriate health-service response to violence against women. Lancet. 2002; 359(9316):1509-1514.

12. Nagae M, Dancy BL. Japanese women's perceptions of intimate partner violence (IPV). J Interpers Violence. 2010;25(4):753-766.

13. Hyder AA, Merritt M, Ali J, Tran NT, Subramaniam K, Akhtar T. Integrating ethics, health policy and health systems in low- and middleincome countries: case studies from Malaysia and Pakistan. Bull World Health Organ. 2008;86(8):606-611.

14. Zink T, Regan S, Goldenhar L, Pabst S, Rinto B. Intimate partner violence: what are physicians' perceptions? J Am Board Fam Pract. 2004;17(5):332-340.

15. Rabbani F, Qureshi F, Rizvi N. Perspectives on domestic violence: case study from Karachi, Pakistan. East Mediterr Health J. 2008;14(2): 415-426.

16. Malik S, Courtney K. Higher education and women an empowerment in Pakistan. Gend Educ. 2011;23(1):29-45.

17. Ali TS, Mogren I, Krantz G. Intimate partner violence and mental health effects: a population-based study among married women in Karachi, Pakistan. Int J Behav Med. 2011;1-2.

18. Karmaliani R, Asad N, Bann CM, et al. Prevalence of anxiety, depression and associated factors among pregnant women of Hyderabad, Pakistan. Int J Soc Psychiatry. 2009;55(5):414-424.

19. Nasrullah M, Haqqi S, Cummings KJ. The epidemiological patterns of honour killing of women in Pakistan. Eur J Public Health. 2009; 19(2):193

20. Fikree FF, Jafarey SN, Korejo R, Afshan A, Durocher JM. Intimate partner violence before and during pregnancy: experiences of postpartum women in Karachi, Pakistan. J Pak Med Assoc. 2006;56(6):252-257. 
21. Ali TS, Asad N, Mogren I, Kruntz G. Intimate partner violence in urban Pakistan: prevalence, frequency, and risk factors. Int J Women Health. 2011:3:105-115.

22. Chotani HA, Razzak JA, Luby SP. Patterns of violence in Karachi, Pakistan. Inj Prev. 2002;8(1):57-59.

23. Cohen MM, Forte T, Du Mont J, Hyman I, Romans S. Intimate partner violence among Canadian women with activity limitations. J Epidemiol Community Health. 2005;59(10):834-839.

24. Graneheim UH, Lundman B. Qualitative content analysis in nursing research: concepts, procedures and measures to achieve trustworthiness. Nurse Educ Today. 2004;24:105-112.

25. Krishnan S, Rocca CH, Hubbard AE, Subbiah K, Edmeades J, Padian NS. Do changes in spousal employment status lead to domestic violence? Insights from a prospective study in Bangalore, India. Soc Sci Med. 2010;70(1):136-143.

26. Myers JE, Madathil J, Tingle LR. Marriage satisfaction and wellness in India and the United States: A preliminary comparison of arranged marriages and marriages of choice. J Couns Dev. 2005;83(2):183-190.

27. Hyder AA, Noor Z, Tsui E. Intimate partner violence among Afghan women living in refugee camps in Pakistan. Soc Sci Med. 2007;64(7):1536-1547.

28. Jackson PL. Mental health symptoms of women in domestic violence relationships. 2011.

29. Vung ND, Krantz G. Childhood experiences of interparental violence as a risk factor for intimate partner violence: a population-based study from northern Vietnam. J Epidemiol Community Health. 2009;63:708-714.
30. Al-Ali N, Pratt N. Conspiracy of near silence: violence against Iraq women. Middle East Rep. 2011;258:34-37.

31. Noor MJ. Daughters of Eve: Violence against women in Pakistan. Unpublished master's thesis. Massachusetts Institute of Technology. Available from: http://dspace mit edu/handle/17211/7582. 2004.

32. Ali TS, Krantz G, Gul R, Asad N, Johansson E, Mogren I. Gender roles and their influence on life prospects for women in urban Karachi, Pakistan: a qualitative study. Glob Health Action. 2011;4(7448): $1-9$.

33. Korat $\mathrm{O}$. How accurate can mothers and teachers be regarding children's emergent literacy development? A comparison between mothers with high and low education. Early Child Dev Care. 2009;179(1):27-41.

34. Abramsky T, Watts C, Garcia-Moreno C, et al. What factors are associated with recent intimate partner violence? Findings from the WHO multi-country study on women's health and domestic violence. BMC Public Health. 2011;11(1):109.

35. Sexual Violence Research Initiative (SVRI) Gender and Health Research Unit, Medical Research Council of South Africa. Sexual violence in Latin America and the Caribbean: a desk review. 2010. Available from: http://www.svri.org/SexualViolenceLACaribbean.pdf. Accessed August $31,2012$.

36. Hinkel E. Handbook of Research in Second Language Teaching and Learning. Mahwah, NJ: Lawrence Erlbaum Associates; 2005.
International Journal of Women's Health

\section{Publish your work in this journal}

The International Journal of Women's Health is an international, peerreviewed open-access journal publishing original research, reports, editorials, reviews and commentaries on all aspects of women's healthcare including gynecology, obstetrics, and breast cancer. The manuscript management system is completely online and includes

\section{Dovepress}

a very quick and fair peer-review system, which is all easy to use. Visit http://www.dovepress.com/testimonials.php to read real quotes from published authors. 